\title{
Isolation and Characterization of GDP-L-Galactose Phosphorylase Gene of Vitamin C Biosynthesis Pathway from Kiwi
}

\author{
Soraya Shiri ${ }^{1}$, Alireza Zebarjadi ${ }^{*}$ \\ ${ }^{1}$ Campus of Agriculture and Natural Resources, Razi University, Kermanshah, Iran
}

Corresponding Author: Alireza Zebarjadi, PhD, Associate Professor, Campus of Agriculture and Natural Resources, Razi University, Kermanshah, Iran. Email: Zebarjadiali@yahoo.com

Received January 25, 2017; Revised March 10, 2018; Accepted April 5, 2018; Online Published June 20, 2018

\begin{abstract}
Introduction: Vitamin $\mathrm{C}$ is a major antioxidant in plants and plays an important role in reducing the activity of reactive oxygen species. In humans, the main role of this molecule is the elimination of activity of active oxygen species along with being cofactor for many enzymes. Human is one of the few mammalian species that can not synthesize this vitamin and needs to get it through food sources. The GDP-Lgalactose phosphorylase (GGP) gene is one of the most important genes in the biosynthetic pathway of vitamin $\mathrm{C}$, which codes for the GDPL-galactose phosphorylase enzyme. Isolation of GGP gene is an important step in transferring it to elevate vitamin C biosynthesis in plants.

Materials and Methods: In current study, the isolation of this gene from kiwi plant was carried out and then was cloned in the pTG19-T plasmid via T/A cloning and subsequently sequenced to confirm it.

Results: Sequencing analysis of the GGP gene showed that this fragment contains $1383 \mathrm{bp}$ and the start and stop codons were ATG and TGA, respectively. The bioinformatics analysis of this gene can provide important information on gene and protein structure. The alignment of cloned sequence was done with other Actinidia DNA sequences. The results based on neighbor-joining alignment showed that some of the mutations in nucleotides were related to the third nucleotide in a specific codon. Also, the minimum distance of protein sequences was observed between isolated GGP and Actinidia chinensis.

Conclusions: Based on analyses, isolated gene (GGP) can be used for increase vitamin $C$ content in other plants such as cucumber and for resistance to environmental stresses in different plants.

Keywords: Actinida deliciosa, GDP-L-galactose phosphorylase (GGP) gene, Kiwi, T/A cloning, Vitamin C

Citation: Shiri S, Zebarjadi A. Isolation and characterization of GDP-L-galactose phosphorylase gene of vitamin C biosynthesis pathway from Kiwi. J Appl Biotechnol Rep. 2018;5(2):59-63. doi:10.29252/jabr.05.02.04.
\end{abstract}

\section{Introduction}

Vitamin $\mathrm{C}$ is a common name of L-ascorbic acid (AsA) that derived from a six-carbon sugar (L-threo-hex-2-enono1,4-lactone). ${ }^{1}$ Vitamin $\mathrm{C}$ is a water-soluble antioxidant that has a predominantly protective role and acts as a cofactor in the synthesis of carnitine and collagen requirement of cardiovascular function, repair, and maintenance of cartilage, bone, and teeth. It also acts as an important component of the skin, scar tissue, tendons, ligaments and blood vessels, as well as the development of immune cells and iron absorption, and is necessary for healing. Human beings with other primates, bats, and guinea pigs aren't able to synthesize it, so they have to obtain through food sources. ${ }^{2,3}$ As vitamin C is soluble in water, it would easily dispose of the body and is not stored. Therefore, it must be supplied by food sources.

Although we can obtain vitamin $\mathrm{C}$ from fresh meat, it degrades by warming the meat and usually vitamin $\mathrm{C}$ provided from plant sources. There is a high level of vitamin $\mathrm{C}$ in vegetables and fruits while usually seeds and dry seeds have a low level of vitamin C. ${ }^{2,4}$

The Smirnov-Wheeler pathway is one of the most important pathways for ASA biosynthesis in plants which consists of GDP-D-mannose and contains L-galactose arrangement. ${ }^{5}$ GDP-L-galactose phosphorylase (GGP) enzyme is responsible for conversion of GDP-L-galactose to L-galactose-1-P in the first step of the Smirnov-Wheeler pathway in plants. This enzyme is coded by GGP and also called VTC2, knows as first regularly point in vitamin $\mathrm{C}$ pathway (Figure 1).

In this regard, over-expression of GGP in plants can significantly increase the concentration of ascorbate in the tissues. ${ }^{6,7}$ In order to increase vitamin C, GGP gene was isolated from kiwi and transferred to the Arabidopsis plant As a result, increasing the expression of GGP gene increased the content of vitamin $\mathrm{C}$ in the Arabidopsis leaf up to

Copyright (C) 2018 The Author(s). This is an open-access article distributed under the terms of the Creative Commons Attribution License (http:// creativecommons.org/licenses/by/4.0), which permits unrestricted use, distribution, and reproduction in any medium, provided the original work is properly cited. 


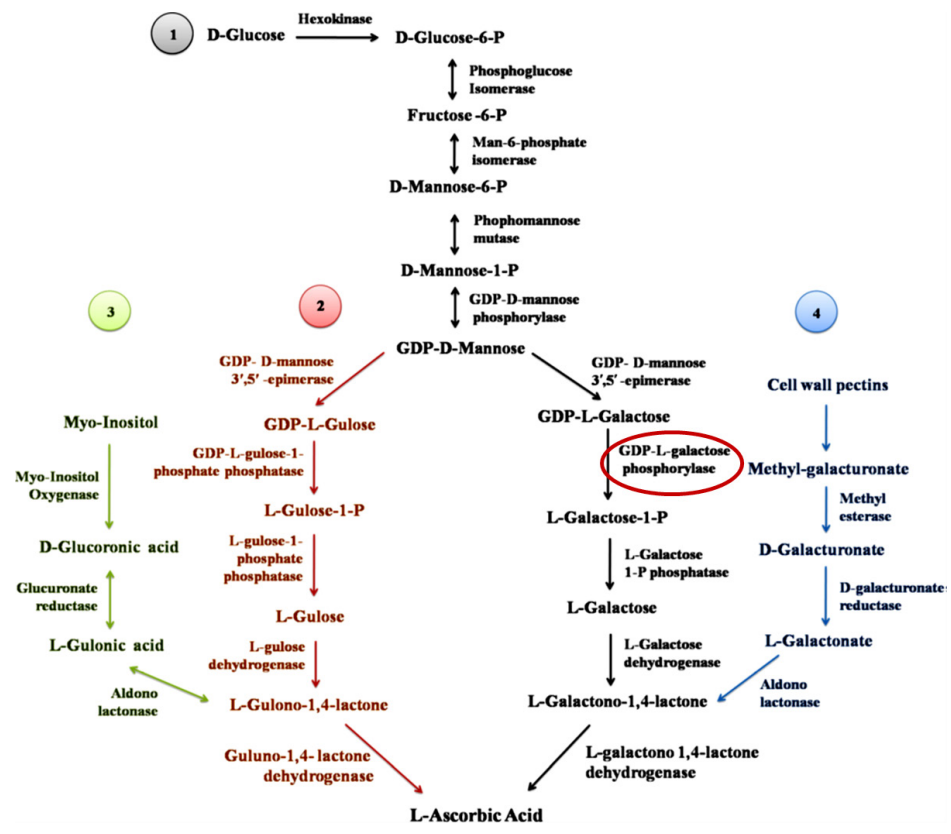

Figure 1. Vitamin C Biosynthesis Pathway. 1: Smirnov-Wheeler pathway, 2: L-glucose pathway, 3: Direction based on Myo-Inositol pathway, 4: D-glucuronic acid pathway.

4-folds. ${ }^{7}$ The purpose of this study was isolation, cloning and characterization of the gene encoding the GGP enzyme.

\section{Materials and Methods}

Experimental Reagents

T4 DNA ligase, Taq DNA polymerase, DNA restriction enzymes, One Step RT-PCR Master Mix, RNA extraction and DNA gel extraction kits were supplied from Ferments Company. The Escherichia coli DH5 <alpha> was used in all molecular biological experiments. Plasmid of pTG19 was used for cloning and sequencing.

\section{RNA Isolation}

Total RNA was isolated from Actinida deliciosa by RNA extraction Ribospin ${ }^{\mathrm{TM}}$ Plant kit. Its quality and quantity were analyzed by gel electrophoresis and spectrophotometer, respectively. Total extracted RNA was used as template for Reverse transcription polymerase chain reaction (RT-PCR) reaction to make cDNA. The $\mathrm{CDNA}$ was used as template for PCR reaction for isolate GGP gene.

\section{Primer Design and PCR Amplification}

The GGP gene of A. deliciosa amplified by PCR using EX Taq DNA polymerase and specific primers GGPF: 5 ' aga GGATCC actagt ATG ttg aag atc aag agg gtt $\mathrm{c} 3^{\prime}$ with a BamHI and SpeI site at the $5^{\prime}$ end (underlined) and GGPR: $5^{\prime}$ cat GAGCTC cacgtg TCA gtg ctg aac tag gca t $3^{\prime}$ with SacI and PmlI site at the $5^{\prime}$ end (underlined). These primers were synthesized based on the reported GGP gene sequences of kiwifruit available at NCBI (GenBank accession number: GU339036, KC146048.1, KC146049.1, EF379384.1).

\section{Cloning and Sequencing}

The PCR product was extracted by a DNA gel extraction kit (South Korea’s GeneAll Company's DN kit) and ligated to
pTG19 plasmid with T4 DNA ligase and then transferred to competent cells of $E$. coli by means of heat shock method. For transformation $200 \mu \mathrm{L}$ of competent cells and $20 \mu \mathrm{l}$ of recombinant vector (pTG19 + Insert) were placed on ice for 30 minutes, followed by a heat shock at $37^{\circ} \mathrm{C}$ for 5 minutes and placed back on ice for 2 minutes. Then $1 \mathrm{ml}$ of $\mathrm{LB}$ medium without antibiotic was added and incubated at $37^{\circ} \mathrm{C}$ for 2 hours with $180 \mathrm{rpm}$ agitation. The bacterial solution was separated on a selectable solid LB medium containing $100 \mathrm{mg}$ $\mathrm{I}^{-1}$ ampicillin and incubated at $37^{\circ} \mathrm{C}$ for 16 hours for selection of recombinant bacteria. Molecular analyses (such as; colony PCR, digestion with restriction enzyme and sequencing) were performed to verify the presence of the distinct insert. Plasmid was purified for sequencing using the standard method. ${ }^{9}$ Sequencing was performed with M13F and T7 standard primers, using the capillary method with $\mathrm{ABI}$ system by Macro gene, Korea.

\section{Ethical Considerations}

This article does not contain any studies with human participants or animals performed by any of the authors.

\section{Results}

The GGP gene fragment (1383 bp) was obtained by PCR reaction via specific primers GGPF and GGPR (Figure 2). The GGP was cloned into the pTG19 plasmid. The positive colonies were confirmed by colony PCR, digestion with restriction enzymes (BamHI and SacI) and sequencing with $\mathrm{M} 13 \mathrm{~F}$ and T7 standard primers. Sequencing analysis of the GGP gene showed that this fragment contains $1383 \mathrm{bp}$ and the start and stop codons were ATG and TGA respectively (Figure 3).

Our sequence was submitted to NCBI server (https://www. ncbi.nlm.nih.gov) for blasting. Various GGP sequences (18 accession numbers) were extracted from GenBank. Four 


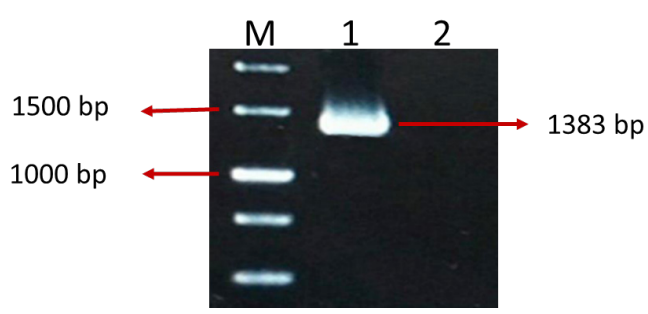

Figure 2. GGP Gene Amplification. M: DNA size Marker (1 Kb), PCR amplification of this gene is shown in lane 1 and Negative control in lane 2 .

sequences belonged to Actinidia (GU339036, KC146048.1, KC146049.1 and EF379384.1). After studying the available sequences in the NCBI data bank, 18 sequences were chosen based on the complete encoding sequence (Table 1).

The alignment of our sequence was done with other Actinidia DNA sequences. The results based on NeighborJoining alignment showed that some of the mutations in nucleotides were related to the third nucleotide in a specific codon; in fact, with the nucleotide change, only codon usage changed and the amino acid remained unchanged. We see a change in the type of amino acid that is identified in yellow (Table 2).

Also, the nucleotide position number 745 that shown by $\mathrm{R}$ in NCBI bank had the high exchange rate of nucleotide. ${ }^{6}$

We used a web based translation tool (https://web.expasy. org/translate) for translating our sequence to protein sequence (Figure 3), then we aligned all 18 chosen protein sequences and our protein sequence by UPGMA method. The phylogenic tree showed that the 18 sequences were placed into six groups, our sequence and five of them (Actinidia deliciosa, Actinidia eriantha, Actinidia rufa, Camellia sinensis, Actinidia chinensis), were located into a group (group 2). Also, the minimum distance of sequences was observed between GGP CLON and Actinidia chinensis. The highest distance between GGP CLON, Actinidia chinensis, Zea mays was observed (Figure 4).

After studying the reported sequences for GGP gene in NCBI, 18 sequences were chosen (Table 1 ) and they were aligned by the MEGA7 software and based on UPGMA method with our sequence the phylogenic tree was reconstructed (Figure 4). The Phylogenic tree showed that 18 sequences were placed into ten groups, our sequence and five of them (A. deliciosa,

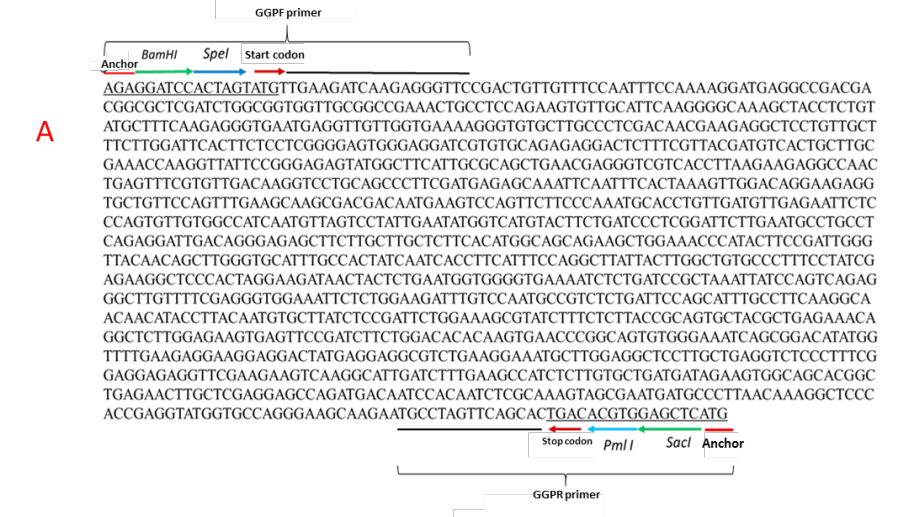

B MLKIKRVPTVVSNFQKDEADDGARSGGGCGRCL QKCCIQGAKLPLYAFKRVNEVVGEKGVLALDNEEA PVAFLDSLLLGEWEDRVQRGLFRYDVTACETKVIP GEYGFIAQLNEGRHLKKRPTEFRVDKVLQPFDESK FNFTKVGQEEVLFQFEASDDNEVQFFPNAPVDVE NSPSVVAINVSPIEYGHVLLIPRILECLPQRIDRESF LLALH Met AAEAGNPYFRLGYNSLGAFATINHLHF QAYYLAVPFPIEKAPTRKITTLNGGVKISDPLNYPV RGLVFEGGNSLEDLSNAVSDSSICLQGNNIPYNVLI SDSGKRIFLLPQCYAEKQALGEVSSDLLDTQVNPA VWEISGH Met VLKRKEDYEEASEGNAWRLLAEVSL SEERFEEVKALIFEAISCADDRSGSTAENLLEEPDD NPQSRKVANDALNKGSHRGMetVPGKQECLVQH

Figure 3. Sequence Analysis of GGP Gene and Predicted Protein Sequence. A: DNA sequence with primers site, start and stop codons and restriction enzyme sites. B: predicted protein sequence of GGP gene (https://web. expasy.org/translate).

A. rufa, A. chinensis, A. eriantha and C. sinensis) were located in the same group (group 1).

The studies showed that phylogenic trees (for DNA and protein) have different groups. Also, Zea mays, Zea mays(2) and Malus domestica plants separately formed a group.

In the protein phylogenic tree, Moringa oleifera and Malpighia glabra were grouped in one group that indicates, they have more similarity in protein sequences, despite the difference in their DNA sequences.

\section{Discussion}

In this research, the GGP gene was isolated from the cDNA of A. deliciosa and subcloned into pTG19-T vector for sequencing. Result of sequencing showed the cDNA of AcGGP had a 1383 bp open reading frame (ORF). Whereas, Linster

Table 1. Information Sequences Used for Alignment

\begin{tabular}{|c|c|c|c|c|c|}
\hline Plant & Gene bank & Pro ID & Plant & Gene bank & Pro ID \\
\hline Our GGP Clone & - & - & Arabidopsis thaliana & AF508793.1 & AAM34266.1 \\
\hline Actinidia deliciosa & GU339036.1 & ADB85572.1 & Arabidopsis thaliana & NM_124894.5 & NP_200323.1 \\
\hline Actinidia rufa & KC146048.1 & AGO32051.1 & Nicotiana tabacum & NM_001324638.1 & NP_001311567.1 \\
\hline Moringa oleifera & AB924665.1 & BAP76192.1 & Nicotiana tabacum & KJ808752.1 & All99836.1 \\
\hline Brassica rapa & JN157614.1 & AET14214.1 & Actinidia eriantha & KC146049.1 & AGO32052.1 \\
\hline Camellia sinensis & KC505203.1 & AGI78464.1 & Actinidia chinensis & EF379384.1 & ABP65665.1 \\
\hline Malpighia glabra & EU683446.1 & ACG75920.1 & Solanum lycopersicum & JQ517313.1 & AFD54988.1 \\
\hline Malus domestica & NM_001293885.1 & NP_001280814.1 & Zea mays & EU966173.1 & ACG38291.1 \\
\hline Solanum tuberosum & NM_001288371.1 & NP_001275300.1 & Zea mays & EU961505.1 & ACG33623.1 \\
\hline Solanum tuberosum & NM_001288264.1 & NP_001275193.1 & & & \\
\hline
\end{tabular}


Table2 . Mutation Point in all Actinidia Species

\begin{tabular}{|c|c|c|c|c|c|}
\hline Nucleotide Number & Clone GGP & Actinidia deliciosa & Actinidia rufa & Actinidia eriantha & Actinidia chinensis \\
\hline 33 & $\mathrm{~T}$ & $\mathrm{~T}$ & $\mathrm{~T}$ & $\mathrm{~T}$ & $\mathrm{C}$ \\
\hline 60 & $\mathrm{C}$ & A & $\mathrm{C}$ & $\mathrm{C}$ & G \\
\hline 75 & $\mathrm{~T}$ & $\mathrm{~T}$ & $\mathrm{~T}$ & $\mathrm{~T}$ & $\mathrm{C}$ \\
\hline 129 & G & G & A & G & G \\
\hline 159 & $\mathrm{~T}$ & G & $\mathrm{T}$ & $\mathrm{T}$ & A \\
\hline 181 & G & $\mathrm{T}$ & G & G & $\mathrm{T}$ \\
\hline 190 & $\mathrm{C}$ & G & $\mathrm{C}$ & $\mathrm{C}$ & G \\
\hline 196 & A & G & A & A & G \\
\hline 220 & $\mathrm{~T}$ & $\mathrm{~T}$ & $\mathrm{C}$ & $\mathrm{T}$ & $\mathrm{T}$ \\
\hline 228 & A & G & G & A & A \\
\hline 234 & $\mathrm{C}$ & $\mathrm{T}$ & $\mathrm{T}$ & $\mathrm{C}$ & $\mathrm{T}$ \\
\hline 276 & $\mathrm{~T}$ & $\mathrm{C}$ & $\mathrm{C}$ & C & C \\
\hline 312 & G & A & A & G & A \\
\hline 337 & C & C & C & C & $\mathrm{T}$ \\
\hline 387 & C & C & $\mathrm{T}$ & $\mathrm{T}$ & C \\
\hline 423 & $\mathrm{~T}$ & $\mathrm{~T}$ & $\mathrm{~T}$ & C & $\mathrm{T}$ \\
\hline 473 & A & A & A & $\mathrm{T}$ & A \\
\hline 492 & C & C & C & $\mathrm{T}$ & C \\
\hline 507 & $\mathrm{~T}$ & $T$ & $\mathrm{~T}$ & $T$ & G \\
\hline 586 & C & $\mathrm{T}$ & C & C & C \\
\hline 587 & G & C & G & G & G \\
\hline 608 & A & G & A & A & A \\
\hline 669 & A & G & G & G & G \\
\hline 708 & $\mathrm{C}$ & A & $\mathrm{C}$ & C & $\mathrm{C}$ \\
\hline 723 & $\mathrm{~T}$ & $\mathrm{~T}$ & $\mathrm{~T}$ & $\mathrm{~T}$ & A \\
\hline 744 & G & G & A & A & A \\
\hline 745 & G & $\mathrm{R}$ & G & G & G \\
\hline 747 & $\mathrm{~T}$ & C & $\mathrm{T}$ & $\mathrm{T}$ & $\mathrm{T}$ \\
\hline 756 & $\mathrm{~T}$ & C & $\mathrm{T}$ & $\mathrm{T}$ & $\mathrm{T}$ \\
\hline 765 & G & G & A & G & G \\
\hline 770 & C & $\mathrm{T}$ & $\mathrm{C}$ & C & C \\
\hline 819 & $\mathrm{~T}$ & G & $\mathrm{T}$ & G & $\mathrm{T}$ \\
\hline 821 & C & $\mathrm{T}$ & $\mathrm{T}$ & $\mathrm{T}$ & $\mathrm{T}$ \\
\hline 865 & $\mathrm{~T}$ & A & $\mathrm{T}$ & $\mathrm{T}$ & $\mathrm{T}$ \\
\hline 888 & C & A & C & C & C \\
\hline 889 & G & G & A & G & G \\
\hline 916 & G & G & G & A & G \\
\hline 961 & C & C & C & C & $\mathrm{T}$ \\
\hline 963 & $\mathrm{~T}$ & G & $\mathrm{T}$ & C & $\mathrm{T}$ \\
\hline 972 & $\mathrm{C}$ & $\mathrm{T}$ & $\mathrm{C}$ & C & C \\
\hline 978 & G & A & G & A & G \\
\hline 984 & C & $\mathrm{T}$ & C & $\mathrm{T}$ & C \\
\hline 987 & C & C & C & $\mathrm{T}$ & C \\
\hline 999 & G & G & G & A & G \\
\hline 1018 & $\mathrm{~T}$ & $\mathrm{~T}$ & C & $\mathrm{T}$ & $\mathrm{T}$ \\
\hline 1020 & C & $\mathrm{T}$ & C & C & C \\
\hline 1023 & $T$ & G & $\mathrm{T}$ & G & $\mathrm{T}$ \\
\hline 1099 & G & G & $\mathrm{C}$ & C & G \\
\hline 1107 & G & G & A & G & G \\
\hline 1164 & C & C & $\mathrm{T}$ & C & C \\
\hline 1213 & A & G & A & A & A \\
\hline 1227 & G & A & G & G & G \\
\hline 1240 & C & C & C & G & C \\
\hline 1255 & G & G & G & A & G \\
\hline 1257 & C & $\mathrm{T}$ & A & C & C \\
\hline 1258 & A & A & A & G & A \\
\hline 1263 & A & $\mathrm{T}$ & A & $\mathrm{T}$ & A \\
\hline 1271 & G & G & A & G & G \\
\hline 1272 & C & $\mathrm{T}$ & $\mathrm{T}$ & $\mathrm{T}$ & C \\
\hline 1273 & A & G & G & G & A \\
\hline 1277 & $\mathrm{~T}$ & A & $\mathrm{T}$ & $\mathrm{T}$ & $\mathrm{T}$ \\
\hline 1279 & G & G & A & G & G \\
\hline 1281 & G & A & G & G & G \\
\hline 1301 & G & G & G & C & G \\
\hline 1309 & C & $\mathrm{T}$ & C & C & $\mathrm{C}$ \\
\hline 1311 & A & $\mathrm{T}$ & A & A & A \\
\hline 1323 & A & G & A & A & A \\
\hline 1326 & G & A & G & G & G \\
\hline
\end{tabular}

Red font: effective mutation. 


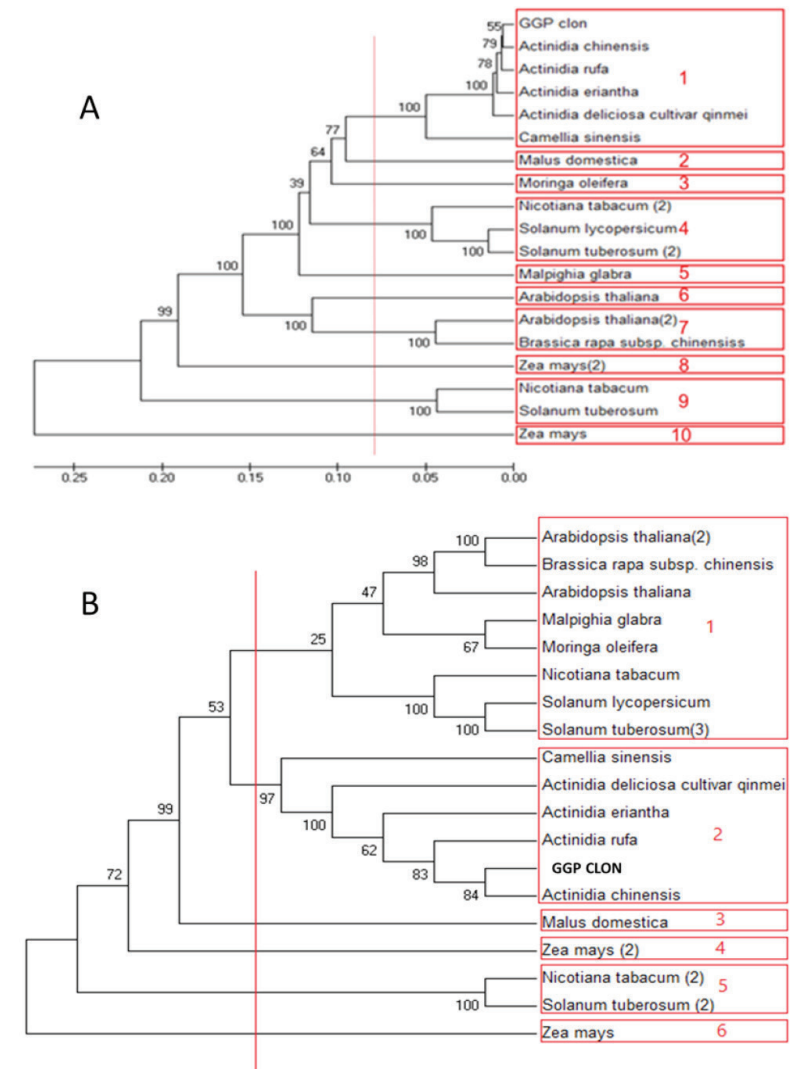

Figure 4. DNA and protein phylogenic tree, A: DNA tree with 10 groups, B: protein tree with 6 groups (by UPGMA method).

et al isolated GGP gene (VTC2 which encodes a GDP-Lgalactose phosphorylase) from cDNA of Arabidopsis thaliana and then cloned in Champion pET100/D-Topo vector. They aligned A. thaliana VTC2 sequence (amino acids) with Oriza sativa, Homo sapines, Caenorhabditis elegans and Drosophila melanogaster. ${ }^{10}$ They found apparent orthologs in invertebrates, vertebrates and plants, including the VTC2 gene product of $A$. thaliana. ${ }^{10}$

In a research, the leaves of the $M$. oleifera used for RNA extraction and cDNA synthesis for isolation of partial GGP gene with primers that was designed based on the conserved amino acid sequences of plant AsA biosynthesis enzymes. The isolated gene was subcloned into the pGEM-T Easy vector and sequenced. Then the gene-specific primers were designed and used for 5'- and 3'-rapid amplification of cDNA ends (RACE) to determine full-length cDNA sequences for Moringa GGP. The cDNA of MoGGP had a 1320 bp ORF that was predicted to encode a protein of 440 amino acids with a calculated molecular mass of $48963 \mathrm{Da}^{1{ }^{11}}$ Primary structure analysis using the Conserved Domain Database (CDD) suggested that MoGGP contains a histidine triad motif found in A. thaliana GGP. ${ }^{11}$ Also they cloned and sequenced the Moringa GGP form genomic sequence. ${ }^{11}$

In a study, Urzica et al reported that the L-galactose pathway of ascorbate biosynthesis described in higher plants is conserved in green algae. They characterized recombinant Chlamydomonas reinhardtii VTC2 as an active GDP-Lgalactose phosphorylase. The VTC2 cDNA was completely sequenced. It contains the entire predicted VTC2 open reading frame, $1857 \mathrm{bp}$ long, encoding a protein of 618 amino acids. BLASTp searches identified a VTC2 homolog in C. reinhardtii exhibits $46 \%$ amino acid sequence identity to $A$. thaliana VTC2. ${ }^{12}$

\section{Conclusions}

Finally, according to our results, isolated GGP gene is a key enzyme in the biosynthetic pathway of L-ascorbic acid and it can be used to express in different plants for increasing vitamin $\mathrm{C}$ content.

\section{Authors' Contributions}

All authors contributed equally to this research.

\section{Conflict of Interest Disclosures}

The authors declare they have no conflicts of interest.

\section{Acknowledgments}

The authors would like to acknowledge all of their friends in the Department of Agronomy and Plant Breeding, Campus of Agriculture and Natural Resources, for their help. The financial support for this work was provided by the Razi University Grant No. 56747.

\section{References}

1. Cruz-Rus E, Amaya I, Valpuesta V. The challenge of increasing vitamin C content in plant foods. Biotechnol J. 2012;7(9):11101121. doi:10.1002/biot.201200041.

2. Gallie DR. L-ascorbic Acid: a multifunctional molecule supporting plant growth and development. Scientifica (Cairo). 2013;2013:795964. doi:10.1155/2013/795964.

3. Gallie DR. Increasing vitamin C content in plant foods to improve their nutritional value-successes and challenges. Nutrients. 2013;5(9):3424-3446. doi:10.3390/nu5093424.

4. Hancock RD, Viola R. Biosynthesis and catabolism of L-ascorbic acid in plants. Critical Reviews in Plant Sciences. 2005;24(3):167188. doi:10.1080/07352680591002165.

5. Wheeler GL, Jones MA, Smirnoff N. The biosynthetic pathway of vitamin C in higher plants. Nature. 1998;393(6683):365-369. doi:10.1038/30728.

6. Li M, Ma F, Liang D, Li J, Wang Y. Ascorbate biosynthesis during early fruit development is the main reason for its accumulation in kiwi. PLoS One. 2010;5(12):e14281. doi:10.1371/journal. pone.0014281.

7. Bulley SM, Rassam M, Hoser D, et al. Gene expression studies in kiwifruit and gene over-expression in Arabidopsis indicates that GDP-L-galactose guanyltransferase is a major control point of vitamin C biosynthesis. J Exp Bot. 2009;60(3):765-778. doi:10.1093/ jxb/ern327.

8. Venkatesh J, Park SW. Role of L-ascorbate in alleviating abiotic stresses in crop plants. Bot Stud. 2014;55(1):38. doi:10.1186/19993110-55-38.

9. Sambrook JR, Russell DW. Molecular cloning: a laboratory manual. Q Rev Biol. 2001;76:348-349.

10. Linster CL, Gomez TA, Christensen KC, et al. Arabidopsis VTC2 encodes a GDP-L-galactose phosphorylase, the last unknown enzyme in the Smirnoff-Wheeler pathway to ascorbic acid in plants. J Biol Chem. 2007;282(26):18879-18885. doi:10.1074/jbc. M702094200.

11. Kondo T, Fujikawa $Y$, Ueda A, et al. Cloning and gene expression analysis of ascorbic acid biosynthesis enzymes in Moringa oleifera. Afr J Agric Sci. 2015;10(22):2274-2285. doi:10.5897/ AJAR2014.9306.

12. Urzica El, Adler LN, Page MD, et al. Impact of oxidative stress on ascorbate biosynthesis in Chlamydomonas via regulation of the VTC2 gene encoding a GDP-L-galactose phosphorylase. J Biol Chem. 2012;287(17):14234-14245. doi:10.1074/jbc.M112.341982.

13. Hemavathi, Upadhyaya $\mathrm{CP}, \mathrm{Akula} \mathrm{N}$, et al. Enhanced ascorbic acid accumulation in transgenic potato confers tolerance to various abiotic stresses. Biotechnol Lett. 2010;32(2):321-30. doi:10.1007/ s10529-009-0140-0. 